\title{
Regulation and functions of bacterial PNPase
}

\begin{tabular}{|r|l|}
\hline Journal: & WIREs RNA \\
\hline Manuscript ID & Draft \\
\hline Wiley - Manuscript type: & Advanced Review \\
\hline Date Submitted by the Author: & n/a \\
\hline Complete List of Authors: & $\begin{array}{l}\text { Briani, Frederica; Università degli Studi di Milano, Dip. di Bioscienze } \\
\text { Carzaniga, Thomas; Università degli Studi di Milano, Dipartimento di } \\
\text { Scienze Biomediche e Cliniche "Luigi Sacco" } \\
\text { Dehò, Gianni; Università degli Studi di Milano, Dip. di Bioscienze }\end{array}$ \\
\hline Keywords: & $\begin{array}{l}\text { PNPase, post-transcriptional regulation, RNA degradation, RNA processing, } \\
\text { DNA repair and recombination, RNA degradosome }\end{array}$ \\
\hline $\begin{array}{r}\text { Choose 1-3 topics to } \\
\text { categorize your article: }\end{array}$ & $\begin{array}{l}\text { Regulation of RNA Stability (RHAC) < RNA Turnover and Surveillance } \\
\text { RHAA), Protein-RNA Interactions-Functional Implications (RDAE) < RNA } \\
\text { Interactions with Proteins and Other Molecules (RDAA) }\end{array}$ \\
\hline
\end{tabular}




\begin{tabular}{|l|l|l|l|}
\hline$\square$ & Overview & $\begin{array}{l}\text { Overviews will provide a broad and relatively non-technical treatment of } \\
\text { important topics at a level suitable for advanced students and for researchers } \\
\text { without a strong background in the field. }\end{array}$ & $\begin{array}{l}5,000-8,000 \text { words } \\
\leq 16 \text { figures/tables } \\
50-100 \text { references }\end{array}$ \\
\hline $\mathbf{X}$ & $\begin{array}{l}\text { Advanced } \\
\text { Review }\end{array}$ & $\begin{array}{l}\text { Advanced Reviews, aimed at researchers and advanced students with a strong } \\
\text { background in the subject, will review key areas of research in a citation-rich } \\
\text { format similar to that of leading review journals. }\end{array}$ & $\begin{array}{l}4,000-6,000 \text { words } \\
\leq 10 \text { figures/tables } \\
50-75 \text { references }\end{array}$ \\
\hline$\square$ & $\begin{array}{l}\text { Focus } \\
\text { Article }\end{array}$ & $\begin{array}{l}\text { Focus articles are short articles, sometimes included within a larger article, } \\
\text { that describe specific real-world issues, examples, implementations, etc. } \\
\text { These articles will be technical in nature. }\end{array}$ & $\begin{array}{l}2,500-4,000 \text { words } \\
\leq 7 \text { figures/tables } \\
40-60 \text { references }\end{array}$ \\
\hline$\square$ & Opinion & $\begin{array}{l}\text { Opinions provide a forum for thought-leaders, hand-picked by the editors, to } \\
\text { provide a more individual perspective on the field in question. }\end{array}$ & $\begin{array}{l}2,000-4,000 \text { words } \\
\leq 5 \text { figures/tables } \\
30-60 \text { references }\end{array}$ \\
\hline
\end{tabular}




\title{
Regulation and functions of bacterial PNPase
}

\author{
Federica Briani*, Thomas Carzaniga ${ }^{1}$ and Gianni Dehò \\ Dipartimento di Bioscienze, Università degli Studi di Milano, Milan, Italy \\ ${ }^{1}$ Present address: Dipartimento di Scienze Biomediche e Cliniche "Luigi Sacco" \\ Università degli Studi di Milano, Milan, Italy \\ *Corresponding author. Mailing address: \\ Dipartimento di Bioscienze \\ Università degli Studi di Milano \\ Via Celoria 26 / A4 \\ 20133 Milano
}

Phone: (+39)02.5031.5033

Fax: (+39)02.5031.5044

E-mail: federica.briani@unimi.it

Keywords: PNPase; post-transcriptional regulation; RNA degradation; RNA processing; DNA repair and recombination; RNA degradosome 


\begin{abstract}
Polynucleotide phosphorylase (PNPase) is an exoribonuclease that catalyzes the processive phosphorolytic degradation of RNA from the 3'-end and the reverse reaction of polymerization of nucleoside diphosphates that generates heteropolymeric tails at the RNA 3'-end. The enzyme is widely conserved and plays a major role in RNA decay in both Gram negative and Gram positive bacteria. Moreover, it participates in maturation and quality control of stable RNA. PNPase autoregulates its own expression at post-transcriptional level through a complex mechanism that involves the endoribonuclease RNase III and translation control. The activity of PNPase is modulated in an intricate and still unclear manner by interactions with small molecules and recruitment in different multiprotein complexes. Not surprisingly, given the wide spectrum of PNPase substrates, PNPase-defective mutations in different bacterial species have pleiotropic effects and perturb the execution of genetic programs involving drastic changes in global gene expression such as biofilm formation, growth at suboptimal temperatures, and virulence. Moreover, PNPase reversibly catalyzes phosphorolysis of ssDNA and is involved in DNA repair and recombination in distantly related bacteria such as Escherichia coli and Bacillus subtilis; it thus appears that this enzyme stands at the crossroad of RNA and DNA worlds.
\end{abstract}

In 1959 Severo Ochoa and Arthur Kornberg were awarded the Nobel Prize "for their discovery of the mechanisms in the biological synthesis of ribonucleic acid and deoxyribonucleic acids", respectively. As for Ochoa, the award referred to his studies on the Azotobacter vinelandii polynucleotide phosphorylase (PNPase, polyribonucleotide nucleotidyltransferase, EC 2.7.7.8), which reversibly catalyzes the 3-'to-5' phosphorolysis of polyribonucleotides, releasing nucleoside diphosphates (NDPs), and the reverse template 
independent 5'-to-3' polymerization of ribonucleoside diphosphates, releasing inorganic phosphate (Pi), ${ }^{1}$ as described by the equation

$$
\mathrm{RNAn}+\mathrm{Pi} \leftrightharpoons \mathrm{RNAn}-1+\mathrm{NDP}
$$

The reversibility of this reaction leads to the exchange between inorganic phosphate and the $\beta$-phosphate of NDPs, a reaction exploited as a sensitive PNPase assay. ${ }^{2,3}$ PNPase was the first enzyme to be found that was "capable of catalyzing the synthesis of RNA... in the test tube from simple, naturally occurring precursors". 4 Soon after, with the discovery of the DNA-dependent RNA polymerase, it became apparent that the template-independent RNA polymerizing activity of PNPase could not be implicated in transcription (Ref. ${ }^{5}$ and references therein) and the reverse reaction, i.e. RNA degradation, was then assumed as the main in vivo activity of this enzyme. ${ }^{6}$ More recently, however, it was shown that PNPase can add heteropolymeric tails to RNA 3'-ends (reviewed in Ref. ${ }^{7}$ ). The biological role of PNPase was far from obvious and six decades of biochemical, genetic and molecular studies delineated a complex scenario leaving several unsolved issues. PNPase is widely conserved in Bacteria and in eukaryotic organelles of bacterial origin (i.e. chloroplasts and mitochondria) with the exception of some unicellular organisms, whereas it is absent from Archaea. ${ }^{8}$ This rather abundant enzyme (PNPase is in the top 5\% of the most expressed proteins in E. coli and other bacteria ${ }^{9}$ ) is finely regulated at the level of its activity by diverse cellular factors and autogenously regulated at post-transcriptional level; PNPase may be associated in macromolecular complexes of diverse composition dedicated to RNA degradation, such as the RNA degradosomes, but also to ribosomes; although in most species analyzed PNPase is not an essential protein, it has been implicated in the control of a variety of complex phenotypes such as response to cold shock, oxidative and other environmental stresses, biofilm formation and virulence. Besides the key role of PNPase in modulating the abundance of a number of mRNAs and small RNAs (sRNAs), and thus the expression of 
many genes, other features have emerged that link this enzyme to DNA metabolism. RNA phosphorolysis generates CDP, a precursors of both CTP and $\mathrm{dCTP} ;{ }^{10} \mathrm{PNPase}$ deficient $E$. coli mutants are more sensitive to $\mathrm{UV}^{11}$ and exhibit a lower frequency of mutation; ${ }^{12}$ remarkably, it was found that PNPase can catalyze template independent synthesis of DNA from dNDPs and DNA phosphorolysis. ${ }^{13-19}$ While initially the latter observation had only practical consequences (PNPase was exploited in the early era of molecular biology for the synthesis of oligoribonucleotides and oligodeoxyribonucleotides), recent data implicate PNPase in DNA recombination, repair, and mutagenesis. ${ }^{11,12,17,18}$

Finally, to further complicate this intricate framework, it is becoming clear that PNPase evolved biochemical peculiarities and different functional properties in different organisms. Thus this review will not aim a full coverage of this pleiotropic and still elusive enzyme; rather it will be focused on the regulation of bacterial PNPase expression and activity, attempting to trace common trends emerging from what, in many cases, are still scattered observations. The most studied E. coli PNPase ( $E c$ PNPase) will be taken as the reference, whereas other bacterial PNPase will be considered to highlight either conserved features or peculiarities of different orthologues.

\section{PNPase CATALYTIC ACTIVITY AND STRUCTURE}

Characterization of enzymatic properties of PNPase from several organisms has been the subject of intense study in the first twenty years after its discovery. The complicated overall picture that emerged has been reviewed by Littauer and Grunberg-Manago. ${ }^{1}$ For our purposes it will be sufficient to remind that PNPase catalysis with ribo-substrates requires $\mathrm{Mg}^{2+}$ and is inhibited by high $\mathrm{Mn}^{2+}$ concentration. ${ }^{4,20}$ On the contrary, polymerization of $\mathrm{dNDPs}$ and DNA phosphorolysis require $\mathrm{Mn}^{2+}$ (or other ions such as $\mathrm{Fe}^{2+}$ ) and are inhibited by $\mathrm{Mg}^{2+} \cdot{ }^{14-18}$ 
Moreover, a large variety of nucleoside diphosphates may serve as substrates for the polymerizing reaction (see for instance Refs. ${ }^{21,22}$ ).

In vivo, the enzyme is an important component of the bacterial RNA decay machinery ${ }^{23}$ and promotes the processive degradation of RNA molecules endowed with 10-12 nt long single stranded 3'-ends. PNPase is stopped by stable secondary structures, ${ }^{24,25}$ however, PNPase promotes also the reverse RNA polymerization reaction, thereby providing the RNA 3'-end with heteropolymeric tails. ${ }^{7}$ In Bacteria, both heteropolymeric- and poly(A) tails, which in $E$. coli are added to the mRNA 3'-end by polyadenylpolymerase (PAPI) have an RNA destabilizing effect, as they function as toeholds for the recruitment of the exoribonucleases involved in RNA decay, which do not bind double stranded RNAs. ${ }^{7,26}$ It has been proposed that, while degrading a single RNA molecule, PNPase could go through cycles of polymerization and phosphorolysis triggered by changes in the local concentration of Pi and NDPs that could be instrumental in attacking structured regions. ${ }^{27}$ Whereas in E. coli both PNPase and PAPI can elongate the RNA 3 '-ends, ${ }^{27-29}$ Streptomyces spp. lacks PAPI and thus RNA-tailing relies on PNPase. ${ }^{30,31}$

PNPase is a homotrimer (Fig. 1A); the 711 aa-long protomer, encoded in E. coli by the pnp gene, is constituted by two RNase PH-like domains (PH1 and PH2; Fig. 1B), supposedly the result of an ancestral duplication event, connected by an all $\alpha$-helical region (AAHD) and followed at the C-terminus by the KH and S1 RNA binding domains. ${ }^{32-34}$ Although the molecular mechanism of PNPase catalysis is still unclear, mutagenesis and structural data locate the active site in the $\mathrm{PH} 2$ region; however, mutations in both $\mathrm{PH} 1$ and AAHD domains affect the enzymatic activity, suggesting that also these domains contribute to the overall architecture of the active site. ${ }^{32,35-37}$ The crystal structures of PNPase from different bacteria and of the $E c$ PNPase-RNA complex have been solved (Fig. 1A). ${ }^{32,34,38,39}$ In the doughnutshaped enzyme, the RNA binding domains are superimposed on the ring made by the six 
RNase PH-like domains. The RNA is fed in the central hole by the S1 and KH RNA binding domains, which contribute to the enzyme processivity. ${ }^{34,40,41}$ Deletion of the S1 and KH domains severely impairs, but does not completely abolish RNA binding, which still occurs at the active site. ${ }^{35,41,42}$ Moreover, although altered in the kinetic behaviour, the mutant PNPase is still enzymatically active, suggesting that the mutation does not compromise the enzyme catalytic site. ${ }^{35,41}$ Interestingly, deletion of the RNA binding domains of Mycobacterium smegmatis PNPase, while affecting RNA phosphorolysis and polymerization, enhances DNA synthesis and degradation by PNPase, suggesting that the S1 and KH domains may also contribute to increase PNPase specificity for RNA $v s$. DNA. ${ }^{19}$

\section{Box 1. A common architecture for RNase PH, PNPase and the exosomes}

The archaeal and eukaryotic exosomes are multiprotein complexes that processively degrade RNA from the 3'-end. They share with the bacterial phosphorolytic exoribonucleasesnucleotidyltransferases PNPase and RNase PH (a prokaryotic enzyme composed of three homodimers and mainly implicated in tRNA processing) a common architecture based on six RNase PH-like domains forming a pseudo-hexameric ring (Fig. 1A) (reviewed by Ref. ${ }^{43}$. The hexameric configuration of the archaeal exosomes is obtained by the assembly of three Rrp41-Rrp42 heterodimers. Since only Rrp41 is catalytically active, the complex has three active sites and, like PNPase, is capped by S1 and KH RNA binding domains that are carried by three copies of the Rrp4 or Csl4 subunits. The eukaryotic exosome is more complex. Its hexameric ring is formed by three catalytically inert RNase PH-like heterodimers (i.e. Rrp41Rrp45, Rrp43-Rrp46 and Mtr3-Rrp42) assembled with three additional subunits on the top of the ring, which provide the RNA binding domains and stabilize the ring. The catalytic activity is conferred by a tenth subunit, either Rrp44 or Rrp6, evolutionarily related to RNase II/R and RNase D, respectively. Thus the eukaryotic exosome, despite its structural 
relatedness with phosphorolytic exoribonucleases and the archaeal exosome, is a hydrolytic RNA-degrading machine. Evolutionarily, it is remarkable that the ancestral RNase $\mathrm{PH}$ imprinted the structure of several enzymes and complexes implicated in the RNA metabolism notwithstanding the loss of its enzymatic activity.

\section{PNPASE IS A COMPONENT OF HETEROGENOUS MULTIPROTEIN COMPLEXES}

PNPase participates in the assembly of multiprotein complexes with variable composition. Early studies discovered that, besides the enzyme A form, which corresponds to the homotrimer, a B form of PNPase was present in crude extract. This heavier form derived from the association of the homotrimer with a dimer of a $48 \mathrm{kDa}$ subunit that was lately identified as the RNA helicase RhlB, which confers to PNPase the ability of degrading structured RNAs. ${ }^{44,45}$ This strongly widens the spectrum of RNAs that can be degraded by PNPase to oligoribonucleotides and in fact the interaction with a helicase represents a conserved feature that bacterial PNPases share not only with their organelle counterparts, but even with the eukaryotic and archaeal exosomes. ${ }^{8}$

The propensity of factors involved in RNA decay to form composite machines, in which different enzymatic activities can be coordinated, has been further substantiated in bacteria by the discovery of the E. coli RNA degradosome, a high molecular weight complex assembled on the C-terminal region of the endonuclease RNase E that includes PNPase, RhlB and the metabolic enzyme enolase. ${ }^{46}$ The definition of "RNA degradosome", however, has been subsequently stretched in order to include a variety of multiprotein complexes involved in RNA decay identified in other bacteria. For instance, in the Gram positive Bacillus subtilis and Staphylococcus aureus RNA degradosomes, RNase E, RhlB, and enolase are replaced by the endonuclease RNase Y, the helicase CshA, and the metabolic enzyme phosphofructokinase as partners of PNPase. ${ }^{47}$ Even in a single bacterial specie as E. coli, the 
composition of the RNA degradosome is highly dynamic and different components, only some of which with an established role in RNA metabolism, are present in substoichiometric amount in degradosome preparations. Moreover, RhlB is replaced by another helicase, CsdA, upon cold shock, a condition that leads to the stabilization of RNA secondary structures. ${ }^{48}$ This suggests that the transient association of different factors may confer peculiar properties to the RNA degradosome that can be instrumental in responding to specific environmental stimuli (Ref. ${ }^{47}$ and references therein).

The assembly of PNPase in multiprotein complexes impacts not only on its physiological role, but also on its spatial localization within the cell. In fact, there is evidence that PNPase, as other components of the RNA degradation apparatus, is not evenly distributed in the cell cytoplasm and that its localization may depend on the association to other factors, in particular RNase E (reviewed by Ref. ${ }^{49}$ ). Indeed, the assembly in the RNA degradosome, which has been reported to interact with translating ribosomes, accounts for the cosedimentation of part of PNPase with the ribosomal fraction, as the co-sedimentation is lost in an RNase E mutant lacking the degradosome scaffold. ${ }^{50-52}$ Moreover, a recent survey of $E$. coli peripherome has detected PNPase and other components of the degradosome among proteins located at the inner face of the cell membrane, in agreement with the documented association of RNase E with the cytoplasmic membrane. ${ }^{47,53}$

Interestingly, the uneven distribution of PNPase-containing RNA degradation machineries is maintained also in other bacteria, such as Caulobacter crescentus, where the RNA degradosome is located in proximity of the nucleoid, and B. subtilis, whose RNase Y-based degradosome is membrane-associated. ${ }^{47}$ The functional consequences of the spatial organization of the RNA decay and the mechanisms of its compartmentalization in the bacterial cells still need to be ascertained. 


\section{REGULATION OF PNPase EXPRESSION AND ACTIVITY}

\section{The $E$. coli pnp gene control: an example of post-transcriptional regulation}

The pnp gene is located immediately downstream of the $r p s O$ gene, ${ }^{54}$ which encodes the ribosomal protein $\mathrm{S} 15$. Regulation of the rpsO-pnp locus mainly occurs at posttranscriptional level, through modulation of mRNA stability and translatability and the study of regulatory mechanisms acting at this locus has greatly contributed to the development of current models of mRNA stability control in Gram-negative bacteria. Control of $r p s O$ expression $^{55}$ (Ref. ${ }^{56}$ and references therein) is largely independent from the autogenous regulation of pnp and will not be hereby reviewed.

Autogenous regulation of pnp in E. coli

The pnp gene can be transcribed from two promoters, namely $\mathrm{P} 1$, located upstream of $r p s O$, and $\mathrm{P} 2$, mapping in the intergenic rpsO-pnp region. ${ }^{57}$ The post-transcriptional regulation steps of PNPase expression are outlined in Fig. 2. Transcripts from both P1 and P2 are quickly and efficiently processed by the endonuclease RNase III, which makes a staggered cut in a long stem-loop located at the 5'-end of the pnp 5'-untranslated region (5'-UTR) (step a), thus generating a new 5'-end of the pnp mRNA (step b) $80 \mathrm{nt}$ upstream of the pnp UUG start codon. (Ref. ${ }^{58}$; our unpublished data). In RNase III-deficient ( $\left.r n c\right)$ mutants, the nonprocessed pnp mRNA is more stable than in $r n c^{+}$strains and PNPase expression increases. ${ }^{59}$, ${ }^{60}$ However, PNPase acts as a translational repressor on the primary (RNase III-unprocessed) pnp mRNAs, ${ }^{61}$ thus exerting a first level of autoregulation. Interestingly, this RNase IIIindependent (RTI) regulatory pathway requires PNPase RNA binding, but not its catalytic activity. ${ }^{61}$ It has been proposed that PNPase represses translation by binding the primary transcript at an unmapped site downstream of the 5 '-stem-loop, in proximity of the translation initiation region (steps $a, b)$. 
Once cleaved by RNase III, the pnp mRNA enters an RNase E-dependent degradative pathway promoted by PNPase (steps b-e). This second autoregulatory mechanism requires both catalytic and RNA binding activities of PNPase. ${ }^{35,37,41,62}$ According to the elegant model proposed by Claude Portier, ${ }^{63}$ after RNase III cleavage, the 5 '-monophosphate end of the processed mRNA remains annealed with a small RNA (sRNA) corresponding to the first 37 nt of the transcripts from P2 (RNA37; step b). This double-stranded structure would protect the mRNA from RNase E. ${ }^{64}$ Then PNPase, with the dispensable assistance of PAPI, ${ }^{63}$, ${ }^{65}$ digests the short RNA, thus releasing the processed pnp mRNA, which is terminally degraded through a PNPase-independent pathway triggered by a first cut by RNase E within the 8th codon of the pnp open reading frame (ORF; step c). ${ }^{66}$ Thus PNPase targets its own messenger to a decay pathway by degrading a sRNA, generated by RNase III cleavage, that protects it from RNase E.

A former model for $p n p$ autoregulation proposed by the same author postulated that PNPase could act as a translational repressor of the processed $p n p$ mRNA by binding to a specific region in the 5 '-UTR and targeting the untranslated mRNA to degradation by other nucleases. ${ }^{67}$ Experimental evidence suggests that translation efficiency may indeed play a role in pnp autoregulation mechanism. In fact, while the primary transcript and the processed mRNA paired with the RNA37 are translatable, the unpaired pnp mRNA seems to be poorly, if at all, translated both in vivo and in vitro. ${ }^{61,63,65}$ The molecular basis of the untranslatability of this mRNA is not known. RNA secondary structure prediction suggests that, in the absence of the interacting RNA37, the mRNA 5'-end could pair with codons 3-7 of the ORF (step d). A hypothesis that awaits experimental testing is that this structure may inhibit translation. This implies that by degrading RNA37, PNPase would promote the transition of the 5'-UTR from a translation-competent to an inhibitory secondary structure that, in turn, would destabilize the pnp untranslated transcript. This could explain the derepressed phenotype 
exhibited by a mutant with a base substitution in the pnp 4th codon (GFX5311 mutant in Ref. ${ }^{67)}$ and would reconcile the current view of PNPase autoregulation ${ }^{63}$ with the former model ${ }^{67}$ by postulating that PNPase could indirectly act as a translational repressor also on the processed pnp mRNA by degrading a translation activator (the RNA37 sRNA). Thus PNPase autoregulates its own expression by several mechanisms. Whereas after the RNase III cleavage PNPase irreversibly targets the $p n p$ mRNA to degradation, the upstream RNase III-independent pathway would represent a reversible step in PNPase autoregulation. What is the relative impact of the two autoregulation steps on PNPase expression and whether it may change in different physiological conditions are open questions. However, as in $r n c^{+}$strains the primary pnp transcript is very quickly processed by RNase III, it is plausible that the RNase III-dependent pathway plays the major role in PNPase expression regulation.

Interestingly, autoregulation of pnp expression involving RNase III-dependent processing of the pnp transcript is a conserved mechanism not only in other Gram negative bacteria such as Photorabdus luminescens, Pseudomonas putida and Yersinia enterocolitica, ${ }^{68-70}$ but also in the soil Gram positive bacterium Streptomyces coelicolor ${ }^{71,72}$ RNase III controls the expression of both stable RNAs and a large number of mRNAs ${ }^{73,74}$ and its activity is affected by a variety of stimuli, including environmental stresses (recently reviewed in Ref. ${ }^{75}$ ). We speculate that the inverse relationship between RNase III activity and PNPase expression might partially compensate RNase III activity variations under certain conditions and provide alternative PNPase-dependent decay pathways to a subset of its target RNAs. The evolutionarily conserved RNase III-dependent regulation of PNPase highlights the need for a coordinate expression of the players of seemingly redundant degradation pathways. 


\section{Cold shock relieves pnp autoregulation}

Cold (i.e. a temperature below $20^{\circ} \mathrm{C}$ cell for mesophilic bacteria) is a physical stress that influences enzyme kinetics, membrane fluidity and affects conformation, topology and reciprocal interactions of macromolecules. In E. coli, during the cold acclimation phase the rate of synthesis of several proteins (cold shock proteins) transiently increases, whereas the synthesis of most other gene products appears to be repressed. Post-transcriptional mechanisms, notably control of mRNA stability and translatability, play a major role in the adaptive response to cold temperature. In particular, mRNA stabilization has been identified as the major factor responsible for the dramatic increase of several cold shock transcripts. ${ }^{76}$ PNPase belongs to the cold shock proteins and its expression transiently increases about twofold in the acclimation phase. However, contrarily to mRNAs of other cold shock genes, pnp transcripts do not seem to be efficiently translated. In fact, in contrast with the two-fold increase of PNPase levels, the cumulative expression of the monocistronic and polycistronic pnp mRNAs, which trespass $p n p$ terminator $t_{p n p}$, rises about 10 -fold in the first two hours after the shift to low temperature. ${ }^{77}$ This enhancement is due to transient suppression of both autoregulation and transcription termination at intrinsic terminators. ${ }^{77-81}$ Whereas abrogation of transcription termination is not specific for the pnp locus, ${ }^{81}$ reversal of autoregulation should occur through a specific mechanism as PNPase appears to be active upon cold shock. ${ }^{79,82,83}$ Although the enzyme is still able to degrade in vitro the RNA37 annealed to the pnp mRNA at $20^{\circ} \mathrm{C},{ }^{63}$ it is possible that in vivo the augmented stability of the RNA duplex may protect the paired RNA37. In agreement with this hypothesis, we observed increased abundance of RNA37 in the acclimation phase (unpublished data). However, differential stability of the RNA duplex at different temperatures cannot be the only operating mechanism, as autogenous regulation occurs at low temperature in acclimated cells. It is possible that upon cold shock, the general impairment of translation may transiently increase 
the pool of ribosomal subunits available for binding, and thus stabilizing, the relatively small number of translation-competent mRNAs, among which the pnp mRNA. Accordingly, at the end of acclimation phase, when general translation resumes, also pnp autoregulation is restored. $^{77}$

PNPase induction in the cold has been reported also for S. coelicolor and the psychrotrophic bacteria P. luminescens and $Y$. enterocolitica. However, in such systems, a different mechanism based on the activation of specific promoters at low temperature is involved. ${ }^{68,69,}$ ${ }^{72}$ Conversely, in $P$. putida, the pnp mRNA level strongly decreases at $9{ }^{\circ} \mathrm{C}$, but the messenger appears to be translatable since the amount of PNPase remains constant in cells growing in the cold. ${ }^{70}$

\section{PNPase activity is modulated by cellular effector molecules}

Another layer of PNPase regulation is modulation of its catalytic activity by several low molecular weight effectors, which connect PNPase enzymatic activity to the cell metabolic state. However, a caveat is needed because for some effectors, the actual in vivo physiological relevance of the in vitro interaction is unsettled.

This is not the case of the Krebs cycle metabolite citrate, whose effect on PNPase has been examined in vitro and in vivo. In particular, magnesium-chelated citrate inhibits PNPase by binding, and conceivably occluding, its catalytic site, whereas the metal-free citrate acts as an allosteric activator of PNPase by interacting with a vestigial active site of the enzyme. In vivo, a PNPase-dependent strain, defective for both RNase II and RNase R, grows slowly on magnesium-citrate; on the other hand, PNPase activity impacts on the cell metabolome. ${ }^{84}$ While this interaction establishes a link between PNPase and the central metabolism, the finding that in vitro EcPNPase is allosterically inhibited by ATP suggests that PNPase activity responds to the cell energy state. ${ }^{85,86}$ In particular, PNPase should be maximally 
active in vivo when the energy charge is low, such as upon transition from exponential to stationary phase and in late stationary phase. ${ }^{87,88}$ Albeit still awaiting an experimental demonstration, this seems a sensible assumption considering that RNA phosphorolysis and tailing by PNPase, by generating and consuming NDPs, respectively, are more energy-saving processes than RNA hydrolysis by ribonucleases, which produce NMPs, and polyadenylation by PAPI, which consumes ATP. ${ }^{85,89}$ Accordingly, the alarmone ppGpp, whose concentration peaks at the entry in stationary phase, ${ }^{87}$ stimulates in vitro the catalytic activity of EcPNPase. ${ }^{86}$ Conversely, the same effector acts as an inhibitor for the PNPase orthologues of the Gram-positive Nonomuraea, which is not affected by ATP, ${ }^{86}$ and Streptomyces. This observation has been rationalized in the light of the rich secondary metabolism of such actinomycetes, which lack RNase II and R and for which shutting off PNPase in stationary phase may represent a strategy to counterbalance the decrease in transcription efficiency by preserving RNA from degradation. ${ }^{86,90}$

All the above effectors have been found to interact with purified PNPase, whereas another modified nucleotide, namely cyclic di-GMP (c-di-GMP), may modulate EcPNPase when the enzyme is part of a specialized RNA degradosome containing, besides RNase E and enolase, the termination factor Rho, the diguanylate cyclase DosC and the phospohodiesterase DosP. Thanks to the interaction with c-di-GMP synthesized by DosC in the presence of oxygen, the activity of PNPase in the complex would be inhibited in aerobiosis. ${ }^{91}$ However, further analyses are required to strengthen this model. In fact, the actual concentration of c-di-GMP associated with the complex at different $\left[\mathrm{O}_{2}\right]$ was not determined, an aspect that appears to be relevant since the c-di-GMP degradative activity of DosP is also activated by oxygen. Moreover, c-di-GMP neither activates nor inhibits purified PNPase. ${ }^{91,92}$

\section{ROLE OF PNPaSe IN RNA DECAY AND QUALITY CONTROL}


RNA degradation relies on the concerted actions of endoribonucleases, which cut RNA at internal sites and in most cases catalyze the first step in RNA decay, and exoribonucleases, which processively degrade from one end the RNA fragments generated by the endoribonucleases. Accessory functions, mainly RNA helicases and enzymes that modify the RNA ends to either facilitate or prevent the access of exoribonucleases to the substrate, are also involved (recently reviewed by ref. ${ }^{93)}$. Besides oligoribonuclease, which degrades RNA fragments 2-5 nt long, the principal E. coli RNA exonucleolytic activities responsible of RNA decay are PNPase and the hydrolytic ribonucleases RNase II and RNase R (encoded by $r n b$ and $r n r$ genes, respectively), which, like PNPase, degrade the RNA from the 3'- to the 5'end without sequence specificity. ${ }^{94}$ Only oligoribonuclease is essential ${ }^{95}$; however, while the cells can tolerate the concomitant lack of RNase II and R, deletion of pnp gene is lethal in the absence of either RNases. ${ }^{24,96}$ This suggests that PNPase can substitute for RNase II and R specific functions that are not shared between the two hydrolytic RNases. Indeed, like RNase R and unlike RNase II, in complex with RhlB or the RNA degradosome PNPase can degrade structured RNA. ${ }^{97,98}$ On the other hand, RNase R, which in the exponential phase is mostly associated with ribosomes, could be targeted to specific decay pathways ${ }^{99}$ thus being not suitable to sustain the entire burden of bulk RNA decay.

\section{Control of mRNA decay by PNPase}

Decay pathways have been analyzed only for a handful of model mRNAs, which have been taken as paradigmatic examples, and mainly in E. coli. ${ }^{100}$ Whereas this has allowed to reconstruct some decay routes that specifically involve different exoribonucleases, the sample of model RNAs is too small to draw general conclusions on the relative impact on gene expression regulation exerted in vivo by each exoribonuclease. Early estimates suggested that degradation of unstable RNA mainly occurs through hydrolysis in E. coli ${ }^{101}$ and that RNase II 
plays quantitatively the most relevant role in RNA degradation in crude extracts. ${ }^{89}$ While it seems sound that this abundant enzyme may have a relevant role in bulk RNA degradation, this does not necessarily implies a major role in mRNA decay. Indeed, spacer regions left by maturation of the rRNA and tRNA primary transcripts or the rRNA itself represent in fast and slowly growing cells, respectively, the most abundant substrates for the degradative machinery. ${ }^{102}$ As a matter of fact, microarray analysis of the transcriptome of $E$. coli mutants lacking either PNPase or RNase II showed that much more mRNAs (17.3\% vs 7.4\%) were overexpressed in the absence of PNPase than RNase II. Conversely, in the RNase II mutant, one third of cellular mRNAs resulted more unstable, suggesting that RNase II may indeed have a protective role on many mRNAs as already shown for the $\operatorname{rps} O$ mRNA. ${ }^{103,104}$ In agreement with these results, a recent RNA-Seq global mRNA profiling of E. coli mutants lacking either PNPase, RNase II or RNase R has shown that the three enzymes control the expression of a comparable number of transcripts (about 200 transcripts each). However, most RNAs were actually destabilized by the absence of RNase II or RNase R (66.9 and 54.5 $\%$, respectively), whereas the lack of PNPase caused an increase in the level of the majority (the $59 \%$ ) of its target RNAs. ${ }^{105}$ On the whole, these data confer a prominent role to PNPase in mRNA degradation.

\section{rRNA and tRNA as PNPase targets}

In E. coli PNPase has been implicated in the processing of 16S rRNA 3'-end ${ }^{106}$ and in the maturation and 3 '-end repair of tRNAs ${ }^{107-110}$, two processes characterized by high redundancy. For instance, besides PNPase, the RNases T, PH, D, II and BN are also implicated in tRNA 3'-end processing; however, in single mutants lacking any of these enzymes, tRNA precursors do not accumulate. ${ }^{111}$ This suggests that several alternative pathways recruiting any of these enzymes can indifferently perform this process. Moreover, 
EcPNPase is involved in quality control pathways that eliminate RNA molecules deriving from the incorrect maturation of $16 \mathrm{~S}$ and $23 \mathrm{~S}$ rRNAs. Also in this case, another exoribonuclease, RNase R, can fully replace PNPase. ${ }^{112}$ The accumulation of RNA fragments interfering with correct ribosome maturation has been causally related to the loss of viability of $r n r$ pnp double mutants, which lacks both enzymes. ${ }^{112}$ PNPase is also implicated in quality control systems that eliminate defective tRNA precursors and in tRNA degradation. ${ }^{105,113}$

Less clear is whether in E. coli PNPase participates in rRNA degradation that occurs upon carbon starvation ${ }^{114,115}$ or at the entry in stationary phase. ${ }^{116}$ On the contrary, in Deinococcus radiodurans, PNPase is converted into a degradation machine specific for structured RNA, named RYPER, by its recruitment in a ribonucleic complex that comprises the Ro orthologue Rsr and the small noncoding Y RNA. Ro protein and Y RNAs, together with La protein, form the core of Ro ribonucleoprotein (RNP) complexes, originally identified in humans as major targets of autoantibodies, whose still controversial functions in animal cells include stabilization of newly synthesized RNA polymerase III transcripts. ${ }^{117}$ In D. radiodurans, RYPER is responsible for extensive rRNA decay in stationary phase. ${ }^{118,119}$ A RYPER-like complex has been purified also from Salmonella enterica and putative Y RNAs have been identified in $>250$ bacteria and phages encoding a Ro orthologue, which have thus the potential to assemble RYPER-like complexes. ${ }^{119,}{ }^{120}$ These findings open the interesting possibility that PNPase, by the assembly in ribonucleic machines with different composition, may acquire specificity towards peculiar classes of RNAs.

\section{Regulation of gene expression by PNPase via degradation and processing of sRNAs Recent research by different groups has revealed a central role exerted by PNPase in the stability control of small noncoding RNAs (sRNAs). ${ }^{105,121}$ It has been suggested that EcPNPase protects several sRNAs from degradation by other nucleases in exponential}


cultures, whereas it would be responsible of their decay upon entry in stationary phase, an activity counteracted by the RNA chaperone Hfq. ${ }^{122-124}$ However, this seems not generally applicable, as some sRNAs appear to be more abundant in exponentially growing cultures of a pnp mutant, suggesting that they could be degraded by PNPase in this growth phase. ${ }^{105}$ Similarly to what occurs with rRNAs and tRNAs, besides its role as a degradative enzyme, PNPase is also responsible for the maturation of some sRNAs from longer RNA precursors, thus implying that depending on the substrate, PNPase can switch from processive RNA digestion to the precise removal of few nucleotides. This is for instance the case of the CI RNA, the immunity factor of bacteriophage P4. PNPase plays a major role, with PAPI, in the correct CI RNA 3'-end formation, which in turn stimulates the 5'-end processing by RNase P. ${ }^{125,126}$ Interestingly, ca. 600 CI-like encoding loci, not necessarily associated with integrated phages, are scattered in sequenced proteobacterial genomes (see c4 antisense RNA motif, Table 1 in ref. ${ }^{127)}$.

Recently, PNPase has been found to be responsible for the maturation of the CRISPR RNA RliB in Listeria monocytogenes; interestingly, PNPase seems to contribute also to the DNA interference activity of $\mathrm{RliB}$. It remains to be established whether PNPase role in this process is restricted to modulation of RliB stability or entails a direct action on DNA. ${ }^{128}$

\section{PNPASE CONTROLS COMPLEX CELL ADAPTIVE RESPONSES}

\section{PNPase is essential for growth at low temperature}

The pnp gene is essential for growth at low temperature in different Gram positive and negative bacteria such as B. subtilis, Campylobacter jejuni, E. coli and Yersinia enterocolitica. ${ }^{69,77,129,130}$ On the other hand, Salmonella enterica serovar Typhimurium pnp mutants show limited cold sensitivity and PNPase is not required for Pseudomonas putida growth at temperature as low as $5{ }^{\circ} \mathrm{C} . .^{70,96,131}$ The hypothesis that PNPase may be involved in 
a cold-essential process conserved in the first group of bacteria and absent in the second one seems unlikely in the light of the lack of correlation between the cold sensitivity of pnp mutants of different bacterial species and their evolutionary distance or adaptation to specific ecological niches. Most likely, in some bacteria the lack of PNPase at low temperature could be at least partially compensated by other factors, and in particular other nucleases. The idea that nuclease-dependent pathways may have partially redundant functions in the cold is supported by the observation that in E. coli, the overexpression of RNase II can suppress the growth defect of a pnp mutant at low temperature. However, $p n p$ strains overexpressing RNase R remain cold sensitive, indicating once again that RNases are not completely interchangeable. $^{132}$

The molecular bases of PNPase essentiality in the cold have been mainly investigated in $E$. coli. In such system, incubation at temperatures $\leq 20{ }^{\circ} \mathrm{C}$ has a bacteriostatic, reversible effect on the growth of pnp mutants, which seem to be stalled in the cold acclimation phase. ${ }^{82}$ Moreover, both PNPase RNA degradation and binding activities are essential in the cold. ${ }^{35,41}$, ${ }^{132}$ On the whole, these observations suggest that PNPase may be required to degrade RNAs that prevent the cells from exiting the cold acclimation phase and resuming growth. Indeed, both in E. coli and in Y. enterocolitica, PNPase is required to promote the degradation of the mRNAs of cold inducible members of CspA family proteins, which are transiently induced in the acclimation phase and have been proposed to sequester the ribosomes. ${ }^{82,83,133-135}$ In fact, ribosomal subunits and monosomes accumulate in a $\Delta p n p$ E. coli strain at $15{ }^{\circ} \mathrm{C}$, suggesting that translation is impaired. ${ }^{132}$

PNPase may be also required for ribosome assembly in the cold. Indeed, in a double pnp rph mutant, which lacks also the second phosphorolytic exoribonuclease RNase $\mathrm{PH}$, the number of $50 \mathrm{~S}$ ribosomal subunits is reduced at $31^{\circ} \mathrm{C}$, but not at $42{ }^{\circ} \mathrm{C}$, and the $23 \mathrm{~S}$ rRNA is 
degraded. ${ }^{133}$ This suggests that ribosome maturation at sub-optimal temperature may require at least one of the phosphorolytic ribonucleases.

\section{PNPase controls the expression of aggregation factors that promote biofilm formation}

Biofilms are multicellular communities of microorganisms adhered to a surface. Biofilm formation is a complex developmental process that involves cell morphological changes, such as the expression of pili at the cell surface and the secretion of an extracellular polymer matrix mainly constituted by exopolysaccharides (EPS). A complex network of regulators including quorum sensing molecules and modified nucleotides controls the transition from planktonic to sessile life style and biofilm maturation. ${ }^{136}$ Evidence from different groups suggest that PNPase contributes to biofilm regulation in E. coli and Salmonella. ${ }^{105,137,138}$ In particular, in E. coli C, PNPase inhibits the synthesis of the EPS poly-N-acetylglucosamine (PNAG) by negatively regulating the PNAG biosynthetic operon pgaABCD at posttranscriptional level through a still unclear mechanism that involves the 5'-UTR of the operon. As a consequence of PNAG overexpression, cellular aggregation and biofilm production are stimulated in a $\Delta p n p$ mutant. ${ }^{137}$ In $E$ coli $\mathrm{K} 12$, mRNAs related to the production of several adhesion factors (including pgaC and pgaD PNAG biosynthetic genes) are specifically overexpressed in $\Delta p n p$, but not in strains lacking either RNase R or II. ${ }^{105}$ However, in such genetic background, the role of PNPase in biofilm formation is less clear as deletion of pnp has been reported to either stimulate ${ }^{137}$ or, as in Salmonella, ${ }^{138}$ prevent $^{105}$ biofilm formation. These differences, whose molecular bases are unknown, could be imputed to strain-specific mechanisms that may have evolved to respond to the variety of environmental signals impacting on biofilm development.

\section{PNPase as a virulence regulator in pathogenic bacteria}


Virulence regulation by PNPase in various bacteria has been recently reviewed ${ }^{139}$ and we will limit here to some general comments. Disparate virulence-related functions respond to PNPase in pathogenic bacteria and the molecular mechanisms by which PNPase controls virulence functions are also variable. Only in some systems PNPase contribution to pathogenesis is clearly imputable to its activity as an exoribonuclease. ${ }^{140}$ In fact, in other cases, PNPase RNA binding rather than enzymatic activity is required for virulence regulation. For instance, PNPase confers increased resistance to killing by murine macrophages to Yersinia pseudotuberculosis and Yersinia pestis, ${ }^{139}$ an effect that has been linked to secretion of Yop effectors by type 3 secretion system (T3SS) specifically promoted by PNPase. Interestingly, the ability to modulate T3SS function is retained by a pnp mutant defective in the catalytic activity, whereas it is lost when the PNPase S1 binding domain is deleted. Moreover, the overexpression of the isolated S1 domain (from PNPase or other proteins) suppresses T3SS downregulation in a pnp deletion mutant. ${ }^{141}$ Overall, these data suggest that PNPase may act in this system by binding (and maybe stabilizing) an unidentified RNA.

Interestingly, while RNase R, like PNPase, has an established function in bacterial pathogenesis $^{142}$ and in growth at low temperature ${ }^{143-145}$ of various bacteria, to our knowledge RNase II has not been found to be essential in the cold or implicated in virulence in any bacteria. It is unclear whether this may reflect an actual specificity in the roles of different bacterial ribonucleases, with overlapping functions between RNase R and PNPase, or only the paucity of studies specifically addressing RNase II role in these phenomena.

\section{PNPase and nucleic acids stress: removal of damaged RNA and DNA repair}

In the last years several apparently unrelated observations implicated PNPase in the response to nucleic acid damage and/or DNA recombination and repair. It should be mentioned that 
although a direct role of PNPase in these mechanisms has been proposed, in most cases an indirect effect of PNPase, which could control the expression of factors operating in the above pathways, has not been ruled out.

Concerning RNA damage, it has been shown that EcPNPase binds RNA containing 8hydroxyguanine (8-oxoG) residues with higher affinity than normal RNA ${ }^{146,147}$ and that PNPase defective E. coli mutants are more sensitive to $\mathrm{H}_{2} \mathrm{O}_{2}$ treatment ${ }^{147}$, which increases the levels of oxidized ribo- and deoxyriboguanosines. Although the effects of RNA modifications on the physiology of the bacterial cell are still largely unexplored, it is believed that, by altering base-pairing interactions, RNA modifications may interfere with the functions of both mRNA and stable RNAs, thus impairing translation and regulation of gene expression. ${ }^{148}$ Thus PNPase, by acting as a specific scavenger of oxidized RNA, may protect the cell from the many harmful consequences caused by oxidized bases.

Recently, PNPase has been implicated in both spontaneous and induced mutagenesis in $E$. coli. $^{12}$ It has been shown that the increased frequency of spontaneous mutations caused by the lack of either the mismatch repair (MMR) system, which corrects spontaneous mutations resulting from replication errors, or the MutT protein, which destroys the pool of oxidized dGTP, is suppressed in pnp deletion mutants. Moreover, such mutants exhibit lower levels of mutagenesis induced by some base analogues such as 5-bromodeoxyuridine. ${ }^{12}$ An explanation of these facts has been related to phosphorolysis of RNA, which generates NDPs that can be converted to dNDPs by ribonucleotide reductase. It was hypothesized that the pool of dNDPs derived from PNPase activity could per se be responsible for the spontaneous mutations observed in MMR- and MutT-deficient backgrounds upon treatment with 5bromodeoxyuridine. ${ }^{12}$ Such hypothesis takes in account only the ability of PNPase to bind and degrade RNA. However, other observations have more directly implicated PNPase in DNA repair and recombination in evolutionary distant bacteria, possibly through its ability to 
bind, degrade and/or polymerize DNA. In B. subtilis PNPase copurifies with RecN, a key protein for the repair of DNA double strand breaks (DSB), ${ }^{149}$ and it is required for the formation of RecN-promoted discrete repair centers upon DNA DSBs induction, where it provides the RecN-associated $3^{\prime} \rightarrow 5^{\prime}$ ssDNA exonucleolytic activity. ${ }^{17,}{ }^{18}$ Notably, unlike $E$. coli, which is endowed with a panoply of $3^{\prime} \rightarrow 5^{\prime}$ exodeoxyribonucleases, $B$. subtilis is lacking other genes encoding such activity. Moreover, PNPase activity on ssDNA degradation and polymerization is modulated in vitro by RecN, RecA, and SSB. ${ }^{17,}{ }^{18}$ In E. coli PNPase was found to co-purify with RecA. ${ }^{150}$ More recently, it was observed that PNPase deficient mutants are sensitive to UV and that in the absence of nucleotide excision repair system, pnp mutants show hypersensitivity to UV radiation. This $p n p$ phenotype is epistatic to $u v r D, r e c B$ and $r u v A$, thus implicating PNPase in the recombinational repair process. ${ }^{11}$

The ability of PNPase to resect and synthesize ssDNA 3'-ends and its interaction with recombination and repair proteins leave open the possibility that PNPase directly participates in recombination, repair and mutagenesis pathways.

\section{CONCLUSION}

After 60 years of research, we are still far from having a complete picture of the multifaceted role played by PNPase in bacterial cells. It is interesting that a "non-essential" protein has been so widely conserved through evolution in Bacteria and Eukarya, notwithstanding the functional redundancy of RNA decay pathways. On the other hand, PNPase exhibits a great evolutionary plasticity as it appears involved in a variety of processes and supramolecular structures in which this protein may play diversified structural and/or enzymatic roles in different bacterial species and eukaryotic organelles. Moreover, the ability to operate on either RNA or DNA, modulated by divalent cations, further expands the repertoire of functions in which PNPase is implicated and opens new research fields that may elucidate 
new interconnections between RNA and DNA metabolism. A deeper knowledge of PNPase assembly in (nucleo)protein complexes like the various RNA degradosomes, RYPERs, and DNA recombination/repair centers, interactions with small molecules, and modulation of its activity in response to growth phase and environmental stimuli is needed to fully understand PNPase physiological role. Lastly, the spatial localization of PNPase and other factors of the RNA decay and DNA transactions apparatus in specific cell districts is a fascinating aspect emerged in the last years. Relating such localization to the functioning of the RNA and DNA transactions machineries is a major challenge for future research in the field.

\section{ACKOWLEDGMENTS}

We would like to thank Sandro Zangrossi and all other past members of our lab that contributed to our research on PNPase. We apologize with all colleagues whose work has not been cited because of space constraints.

\section{REFERENCES}

1. Littauer UZ, and Grunberg-Manago, M. . Polynucleotide phosphrylase. In: Creighton TE, ed. Encyclopedia of Mol Biol. Vol. 3. New York: John Wiley and Sons; 1999, 1911-1918.

2. Grunberg-Manago M, Oritz PJ, Ochoa S. Enzymatic synthesis of nucleic acid-like polynucleotides. Science 1955, 122:907-910.

3. Grunberg-Manago M, Ortiz PJ, Ochoa S. Enzymic synthesis of polynucleotides. I. Polynucleotide phosphorylase of Azotobacter vinelandii. Biochim Biophys Acta 1956, $20: 269-285$. 
4. Ochoa S. Enzymatic synthesis of ribonucleic acid. Nobel Lectures 1959, Stockholm 1959.

5. Kresge N, Simoni, R. D., and Hill, R. L. The discovery and isolation of RNA polymerase by Jerard Hurwitz. J Biol Chem 2006, 281:e12.

6. Deutscher MP, Li Z. Exoribonucleases and their multiple roles in RNA metabolism. Prog Nucl Acid Res Mol Biol 2001, 66:67-105.

7. Mohanty BK, Kushner SR. Bacterial/archaeal/organellar polyadenylation. WIREsRNA 2011, 2:256-276. doi: 10.1002/wrna.51

8. Lin-Chao S, Chiou NT, Schuster G. The PNPase, exosome and RNA helicases as the building components of evolutionarily-conserved RNA degradation machines. $J$ Biomed Sci 2007, 14:523-532. doi: 10.1007/s11373-007-9178-y

9. http://pax-db.org/\#!protein/6883773.

10. Danchin A. Comparison between the Escherichia coli and Bacillus subtilis genomes suggests that a major function of polynucleotide phosphorylase is to synthesize CDP. DNA Res 1997, 4:9-18.

11. Rath D, Mangoli SH, Pagedar AR, Jawali N. Involvement of pnp in survival of UV radiation in Escherichia coli K-12. Microbiology-Sgm 2012, 158:1196-1205. doi: 10.1099/mic.0.056309-0

12. Becket E, Tse L, Yung M, Cosico A, Miller JH. Polynucleotide phosphorylase plays an important role in the generation of spontaneous mutations in Escherichia coli. $J$ Bacteriol 2012, 194:5613-5620. doi: 10.1128/JB.00962-12

13. Kaufmann G, Littauer UZ. Deoxyadenosine diphosphate as substrate for polynucleotide phosphorylase from Escherichia coli. FEBS Lett 1969, 4:79-83. doi: $10.1016 / 0014-5793(69) 80201-2$ 
14. Chou JY, Singer MF. Deoxyadenosine diphosphate as a substrate and inhibitor of polynucleotide phosphorylase of Micrococcus luteus . I. Deoxyadenosine diphosphate as a substrate for polymerization and the exchange reaction with inorganic 32 P. J Biol Chem 1971, 246:7486-7496.

15. Gillam S, Smith M. Enzymatic synthesis of deoxyribo-oligonucleotides of defined sequence. Properties of the enzyme. Nucl Acids Res 1974, 1:1631-1647.

16. Beljanski M. De novo synthesis of DNA-like molecules by polynucleotide phosphorylase in vitro. J Mol Evol 1996, 42:493-499. doi: 10.1007/Bf02352279

17. Cardenas PP, Carrasco B, Sanchez H, Deikus G, Bechhofer DH, Alonso JC. Bacillus subtilis polynucleotide phosphorylase 3'-to-5' DNase activity is involved in DNA repair. Nucl Acids Res 2009, 37:4157-4169. doi: 10.1093/nar/gkp314

18. Cardenas PP, Carzaniga T, Zangrossi S, Briani F, Garcia-Tirado E, Dehò G, Alonso JC. Polynucleotide phosphorylase exonuclease and polymerase activities on singlestranded DNA ends are modulated by RecN, SsbA and RecA proteins. Nucl Acids Res 2011, 39:9250-9261. doi: 10.1093/nar/gkr635

19. Unciuleac MC, Shuman S. Distinctive effects of domain deletions on the manganesedependent DNA polymerase and DNA phosphorylase activities of Mycobacterium smegmatis polynucleotide phosphorylase. Biochemistry 2013, 52:2967-2981. doi: 10.1021/bi400281w

20. Reiner AM. Characterization of polynucleotide phosphorylase mutants of Escherichia coli. J Bacteriol 1969, 97:1437-1443.

21. Kakiuchi N, Fukui T, Ikehara M. Polynucleotides. LVII. Synthesis and properties of poly (2'-chloro-2'-deoxyinosinic acid). Nucl Acids Res 1979, 6:2627-2636. 
22. Kikuchi Y, Hirai K, Sakaguchi K. Novel monofunctional substrates of polynucleotide phosphorylase. The "single-addition" of 2'(3')-O-dihydrocinnamoyl-nucleoside 5'diphosphate to a primer oligonucleotide. J Biochem (Tokyo) 1975, 77:469-472.

23. Silva IJ, Saramago M, Dressaire C, Domingues S, Viegas SC, Arraiano CM. Importance and key events of prokaryotic RNA decay: the ultimate fate of an RNA molecule. WIRES-RNA 2011, 2:818-836. doi: 10.1002/wrna.94

24. Donovan WP, Kushner SR. Polynucleotide phosphorylase and ribonuclease II are required for cell viability and mRNA turnover in Escherichia coli K-12. Proc Natl Acad Sci U S A 1986, 83:120-124.

25. Coburn GA, Mackie GA. Reconstitution of the degradation of the mRNA for ribosomal protein S20 with purified enzymes. J Mol Biol 1998, 279:1061-1074. doi: 10.1006/jmbi.1998.1842

26. Régnier P, Hajnsdorf E. Poly(A)-assisted RNA decay and modulators of RNA stability. Prog Mol Biol Transl Sci 2009, 85:137-185. doi: 10.1016/S00796603(08)00804-0.

27. Mohanty BK, Kushner SR. Polynucleotide phosphorylase functions both as a 3 ' rightarrow 5' exonuclease and a poly(A) polymerase in Escherichia coli. Proc Natl Acad Sci USA 2000, 97:11966-11971. doi: 10.1073/pnas.220295997

28. Cao GJ, Sarkar N. Poly(A) RNA in Escherichia coli: Nucleotide Sequence at the Junction of the Lpp Transcript and the Polyadenylate Moiety. Proc Natl Acad Sci USA 1992, 89:7546-7550. doi: 10.1073/pnas.89.16.7546

29. Mohanty BK, Kushner SR. The majority of Escherichia coli mRNAs undergo posttranscriptional modification in exponentially growing cells. Nucl Acids Res 2006, 34:5695-5704. doi: 10.1093/nar/gk1684 
30. Sohlberg B, Huang J, Cohen SN. The Streptomyces coelicolor polynucleotide phosphorylase homologue, and not the putative poly(A) polymerase, can polyadenylate RNA. J Bacteriol 2003, 185:7273-7278. doi: 10.1128/JB.185.24.72737278.2003

31. Jones GH, Mackie GA. Streptomyces coelicolor polynucleotide phosphorylase can polymerize nucleoside diphosphates under phosphorolysis conditions, with implications for the degradation of structured RNAs. $J$ Bacteriol 2013, 195:51515159. doi: 10.1128/JB.00936-13

32. Symmons MF, Jones GH, Luisi BF. A duplicated fold is the structural basis for polynucleotide phosphorylase catalytic activity, processivity, and regulation. Structure 2000, 8:1215-1226. doi: 10.1016/S0969-2126(00)00521-9

33. Bermudez-Cruz RM, Ramirez F, Kameyama-Kawabe L, Montanez C. Conserved domains in polynucleotide phosphorylase among eubacteria. Biochimie 2005, 87:737745. doi: 10.1016/j.biochi.2005.03.005

34. Shi Z, Yang WZ, Lin-Chao S, Chak KF, Yuan HS. Crystal structure of Escherichia coli PNPase: central channel residues are involved in processive RNA degradation. RNA 2008, 14:2361-2371. doi: 10.1261/rna.1244308

35. Briani F, Del Favero M, Capizzuto R, Consonni C, Zangrossi S, Greco C, De Gioia L, Tortora P, Dehò G. Genetic analysis of polynucleotide phosphorylase structure and functions. Biochimie 2007, 89:145-157. doi: 10.1016/j.biochi.2006.09.020

36. Carzaniga T, Mazzantini E, Nardini M, Regonesi ME, Greco C, Briani F, De Gioia L, Dehò G, Tortora P. A conserved loop in polynucleotide phosphorylase (PNPase) essential for both RNA and ADP/phosphate binding. Biochimie 2014, 97:49-59. doi: 10.1016/j.biochi.2013.09.018 
37. Jarrige A, Brechemier-Baey D, Mathy N, Duche O, Portier C. Mutational analysis of polynucleotide phosphorylase from Escherichia coli. J Mol Biol 2002, 321:397-409. doi: 10.1061/S0022-2836(02)00645-9

38. Hardwick SW, Gubbey T, Hug I, Jenal U, Luisi BF. Crystal structure of Caulobacter crescentus polynucleotide phosphorylase reveals a mechanism of RNA substrate channelling and RNA degradosome assembly. Open Biol 2012, 2:120028. doi: 10.1098/rsob. 120028

39. Nurmohamed S, Vaidialingam B, Callaghan AJ, Luisi BF. Crystal structure of Escherichia coli polynucleotide phosphorylase core bound to RNase E, RNA and manganese: implications for catalytic mechanism and RNA degradosome assembly. $J$ Mol Biol 2009, 389:17-33. doi: 10.1016/j.jmb.2009.03.051

40. García-Mena J, Das A, Sanchez-Trujillo A, Portier C, Montanez C. A novel mutation in the $\mathrm{KH}$ domain of polynucleotide phosphorylase affects autoregulation and mRNA decay in Escherichia coli. Mol Microbiol 1999, 33:235-248. doi: 10.1046/j.13652958.1999.01451.x

41. Matus-Ortega ME, Regonesi ME, Pina-Escobedo A, Tortora P, Dehò G, García-Mena J. The KH and S1 domains of Escherichia coli polynucleotide phosphorylase are necessary for autoregulation and growth at low temperature. Biochim Biophys Acta 2007, 1769:194-203. doi: 10.1016/j.bbaexp.2007.01.008

42. Regonesi ME, Briani F, Ghetta A, Zangrossi S, Ghisotti D, Tortora P, Dehò G. A mutation in polynucleotide phosphorylase from Escherichia coli impairing RNA binding and degradosome stability. Nucl Acids Res 2004, 32:1006-1017. doi: $10.1093 /$ nar/gkh268

43. Januszyk K, Lima CD. Structural Components and Architectures of RNA Exosomes. Adv Exp Med Biol 2010, 702:9-28. doi: 10.1007/978-1-4419-7841-7 
44. Lin PH, Lin-Chao S. RhlB helicase rather than enolase is the beta-subunit of the Escherichia coli polynucleotide phosphorylase (PNPase)-exoribonucleolytic complex. Proc Natl Acad Sci USA 2005, 102:16590-16595. doi: 10.1073/pnas.0500994102

45. Portier C. Quaternary structure of polynucleotide phosphorylase from Escherichia coli: evidence of a complex between two types of polypeptide chains. Eur J Biochem 1975, 55:573-582. doi: 10.1111/j.1432-1033.1975.tb02194.X

46. Bandyra KJ, Bouvier M, Carpousis AJ, Luisi BF. The social fabric of the RNA degradosome. Biochim Biophys Acta 2013, 1829:514-522. doi:

10.1016/j.bbagrm.2013.02.011

47. Aït-Bara S, Carpousis AJ. RNA degradosomes in bacteria and chloroplasts: classification, distribution and evolution of RNase E homologs. Mol Microbiol 2015, 97:1021-1135. doi: 10.1111/mmi.13095

48. Prud'homme-Genereux A, Beran RK, Iost I, Ramey CS, Mackie GA, Simons RW. Physical and functional interactions among RNase E, polynucleotide phosphorylase and the cold-shock protein, CsdA: evidence for a 'cold shock degradosome'. Mol Microbiol 2004, 54:1409-1421.

49. Evguenieva-Hackenberg E, Roppelt V, Lassek C, Klug G. Subcellular localization of RNA degrading proteins and protein complexes in prokaryotes. RNA Biol 2011, 8:4954. doi: 10.4161/rna.8.1.14066

50. Tsai YC, Du D, Dominguez-Malfavon L, Dimastrogiovanni D, Cross J, Callaghan AJ, Garcia-Mena J, Luisi BF. Recognition of the 70S ribosome and polysome by the RNA degradosome in Escherichia coli. Nucl Acids Res 2012, 40:10417-10431. doi:

$10.1093 /$ nar/gks739

John Wiley \& Sons 
51. Delvillani F, Papiani G, Dehò G, Briani F. S1 ribosomal protein and the interplay between translation and mRNA decay. Nucl Acids Res 2011, 39:7702-7715. doi:

\section{$10.1093 / \mathrm{nar} / \mathrm{gkr} 417$}

52. Kimhi Y, Littauer UZ. The intracellular distribution of polynucleotide phosphorylase in Escherichia coli cells. Biochemistry 1967, 6:2066-2073.

53. Papanastasiou M, Orfanoudaki G, Koukaki M, Kountourakis N, Sardis MF, Aivaliotis M, Karamanou S, Economou A. The Escherichia coli peripheral inner membrane proteome. Mol Cell Proteomics 2013, 12:599-610. doi: 10.1074/mcp.M112.024711

54. Portier C, Migot C, Grumberg-Manago M. Cloning of E. coli pnp gene from an episome. Mol Gen Genet 1981, 183:298-305.

55. Régnier P, Hajnsdorf E. Decay of mRNA encoding ribosomal protein S15 of Escherichia coli is initiated by an RNase E-dependent endonucleolytic cleavage that removes the 3' stabilizing stem and loop structure. J Mol Biol 1991, 217:283-292. doi: 10.1016/0022-2836(91)90542-E

56. Andrade JM, Hajnsdorf E, Régnier P, Arraiano CM. The poly(A)-dependent degradation pathway of $r p s O$ mRNA is primarily mediated by RNase R. RNA. 2009, 15:316-326. doi: 10.1261/rna.1197309

57. Portier C, Régnier P. Expression of the rps $O$ and pnp genes: structural analysis of a DNA fragment carrying their control regions. Nucl Acids Res 1984, 12:6091-6102. doi: 10.1093/nar/12.15.6091

58. Régnier P, Portier C. Initiation, attenuation and RNase III processing of transcripts from the Escherichia coli operon encoding ribosomal protein S15 and polynucleotide phosphorylase. J Mol Biol 1986, 187:23-32. doi: 10.1016/0022-2836(86)90403-1 
59. Portier C, Dondon L, Grunberg-Manago M, Régnier P. The first step in the functional inactivation of the Escherichia coli polynucleotide phosphorylase messenger is a ribonuclease III processing at the 5' end. EMBO J. 1987, 6:2165-2170.

60. Takata R, Mukai T, Hori K. RNA Processing by RNase-III is Involved in the Synthesis of Escherichia coli Polynucleotide Phosphorylase. Mol Gen Genet 1987, 209:28-32. doi: 10.1007/Bf00329832

61. Carzaniga T, Dehò G, Briani F. RNase III-independent autogenous regulation of Escherichia coli polynucleotide phosphorylase via translational repression. $J$ Bacteriol 2015. doi: 10.1128/JB.00105-15

62. Wong AG, McBurney KL, Thompson KJ, Stickney LM, Mackie GA. S1 and KH domains of polynucleotide phosphorylase determine the efficiency of RNA binding and autoregulation. $J$ Bacteriol 2013, 195:2021-2031. doi: 10.1128/JB.00062-13

63. Jarrige AC, Mathy N, Portier C. PNPase autocontrols its expression by degrading a double-stranded structure in the pnp mRNA leader. EMBO J 2001, 20:6845-6855. doi: $10.1093 / \mathrm{emboj} / 20.23 .6845$

64. Mackie GA. Ribonuclease E is a 5 '-end-dependent endonuclease. Nature 1998, 395:720-723. doi: $10.1038 / 27246$

65. Carzaniga T, Briani F, Zangrossi S, Merlino G, Marchi P, Dehò G. Autogenous regulation of Escherichia coli polynucleotide phosphorylase expression revisited. $J$ Bacteriol 2009, 191:1738-1748. doi: 10.1128/JB.01524-08

66. Hajnsdorf E, Carpousis AJ, Régnier P. Nucleolytic inactivation and degradation of the RNase III processed pnp message encoding polynucleotide phosphorylase of Escherichia coli. J Mol Biol 1994, 239:439-454. doi: 10.1006/jmbi.1994.1387 
67. Robert-Le Meur M, Portier C. Polynucleotide phosphorylase of Escherichia coli induces the degradation of its RNase III processed messenger by preventing its translation. Nucl Acids Res 1994, 22:397-403. doi: 10.1093/nar/22.3.397

68. Clarke DJ, Dowds BCA. The Gene Coding for Polynucleotide Phosphorylase in Photorhabdus Sp Strain-K122 Is Induced at Low-Temperatures. J Bacteriol 1994, $176: 3775-3784$.

69. Goverde RLJ, Veld JHJHI, Kusters JG, Mooi FR. The psychrotrophic bacterium Yersinia enterocolitica requires expression of pnp, the gene for polynucleotide phosphorylase, for growth at low temperature $\left(5^{\circ} \mathrm{C}\right)$. Mol Microbiol 1998, 28:555569. doi: 10.1046/j.1365-2958.1998.00816.x

70. Favaro R, Dehò G. Polynucleotide phosphorylase-deficient mutants of Pseudomonas putida. J Bacteriol 2003, 185:5279-5286.

71. Gatewood ML, Bralley P, Jones GH. RNase III-dependent expression of the rpsO-pnp operon of Streptomyces coelicolor. J Bacteriol 2011, 193:4371-4379. doi: $10.1128 / \mathrm{Jb} .00452-11$

72. Bralley P, Gatewood ML, Jones GH. Transcription of the rps O-pnp operon of Streptomyces coelicolor involves four temporally regulated, stress responsive promoters. Gene 2014, 536:177-185. doi: 10.1016/j.gene.2013.10.055

73. Drider D, Condon C. The continuing story of endoribonuclease III. J Mol Microbiol Biotechnol 2004, 8:195-200. doi: 10.1159/000086700

74. Stead MB, Marshburn S, Mohanty BK, Mitra J, Pena Castillo L, Ray D, van Bakel H, Hughes TR, Kushner SR. Analysis of Escherichia coli RNase E and RNase III activity in vivo using tiling microarrays. Nucl Acids Res 2011, 39:3188-3203. doi: $10.1093 / \mathrm{nar} / \mathrm{gkq} 1242$ 
75. Lim B, Sim M, Lee H, Hyun S, Lee Y, Hahn Y, Shin E, Lee K. Regulation of Escherichia coli RNase III activity. J Microbiol 2015, 53:487-494. doi: $10.1007 / \mathrm{s} 12275-015-5323-\mathrm{x}$

76. Phadtare S, Alsina J, Inouye M. Cold-shock response and cold-shock proteins. Curr Opin Microbiol 1999, 2:175-180. doi: 10.1016/S1369-5274(99)80031-9

77. Zangrossi S, Briani F, Ghisotti D, Regonesi ME, Tortora P, Dehò G. Transcriptional and post-transcriptional control of polynucleotide phosphorylase during cold acclimation in Escherichia coli. Mol Microbiol 2000, 36:1470-1480. doi: 10.1046/j.1365-2958.2000.01971.x

78. Marchi P, Longhi V, Zangrossi S, Gaetani E, Briani F, Dehò G. Autogenous regulation of Escherichia coli polynucleotide phosphorylase during cold acclimation by transcription termination and antitermination. Mol Genet Genomics 2007, 278:7584. doi: 10.1007/s00438-007-0231-3

79. Beran RK, Simons RW. Cold-temperature induction of Escherichia coli polynucleotide phosphorylase occurs by reversal of its autoregulation. Mol Microbiol 2001, 39:112-125. doi: 10.1046/j.1365-2958.2001.02216.x

80. Mathy N, Jarrige AC, Robert-Le Meur M, Portier C. Increased expression of Escherichia coli polynucleotide phosphorylase at low temperatures is linked to a decrease in the efficiency of autocontrol. $J$ Bacteriol 2001, 183:3848-3854. doi: $10.1128 / \mathrm{Jb} .183 .13 .3848-3854.2001$

81. Bae W, Xia B, Inouye M, Severinov K. Escherichia coli CspA-family RNA chaperones are transcription antiterminators. Proc Natl Acad Sci USA 2000, 97:77847789. 
82. Yamanaka K, Inouye M. Selective mRNA degradation by polynucleotide phosphorylase in cold shock adaptation in Escherichia coli. J Bacteriol 2001, 183:2808-2816. doi: 10.1128/Jb.183.9.2808-2816.2001

83. Polissi A, De Laurentis W, Zangrossi S, Briani F, Longhi V, Pesole G, Dehò G.

Changes in Escherichia coli transcriptome during acclimatization at low temperature. Res Microbiol 2003, 154:573-580. doi: 10.1016/S0923-2508(03)00167-0

84. Nurmohamed S, Vincent HA, Titman CM, Chandran V, Pears MR, Du DJ, Griffin JL, Callaghan AJ, Luisi BF. Polynucleotide Phosphorylase Activity May Be Modulated by Metabolites in Escherichia coli. J Biol Chem 2011, 286:14315-14323. doi: 10.1074/jbc.M110.200741

85. Del Favero M, Mazzantini E, Briani F, Zangrossi S, Tortora P, Dehò G. Regulation of Escherichia coli polynucleotide phosphorylase by ATP. J Biol Chem 2008, 283:27355-27359. doi: 10.1074/jbc.C800113200

86. Siculella L, Damiano F, di Summa R, Tredici SM, Alduina R, Gnoni GV, Alifano P. Guanosine 5 '-diphosphate 3 '-diphosphate (ppGpp) as a negative modulator of polynucleotide phosphorylase activity in a 'rare' actinomycete. Mol Microbiol 2010, 77:716-729. doi: 10.1111/j.1365-2958.2010.07240.x

87. Murray HD, Schneider DA, Gourse RL. Control of rRNA expression by small molecules is dynamic and nonredundant. Mol Cell 2003, 12:125-134. doi: $10.1016 / \mathrm{S} 1097-2765(03) 00266-1$

88. Buckstein MH, He J, Rubin H. Characterization of nucleotide pools as a function of physiological state in Escherichia coli. J Bacteriol 2008, 190:718-726. doi:

10.1128/JB.01020-07 
89. Deutscher MP, Reuven NB. Enzymatic basis for hydrolytic versus phosphorolytic mRNA degradation in Escherichia coli and Bacillus subtilis Proc Natl Acad Sci USA $1991,88: 3277-3280$.

90. Gatewood ML, Jones GH. (p)ppGpp inhibits polynucleotide phosphorylase from streptomyces but not from Escherichia coli and increases the stability of bulk mRNA in Streptomyces coelicolor. J Bacteriol 2010, 192:4275-4280. doi: 10.1128/JB.0036710.

91. Tuckerman JR, Gonzalez G, Gilles-Gonzalez MA. Cyclic di-GMP Activation of Polynucleotide Phosphorylase Signal-Dependent RNA Processing. J Mol Biol 2011, 407:633-639. doi: 10.1016/j.jmb.2011.02.019

92. Tuckerman JR, Gonzalez G, Sousa EH, Wan X, Saito JA, Alam M, Gilles-Gonzalez MA. An oxygen-sensing diguanylate cyclase and phosphodiesterase couple for c-diGMP control. Biochemistry 2009, 48:9764-9774. doi: 10.1021/bi901409g

93. Hui MP, Foley PL, Belasco JG. Messenger RNA degradation in bacterial cells. Annu Rev Genet 2014, 48:537-559. doi: 10.1146/annurev-genet-120213-092340

94. Andrade JM, Pobre V, Silva IJ, Domingues S, Arraiano CM. The role of 3'-5' exoribonucleases in RNA degradation. Prog Mol Biol Transl Sci 2009, 85:187-229. doi: 10.1016/S0079-6603(08)00805-2

95. Ghosh S, Deutscher MP. Oligoribonuclease is an essential component of the mRNA decay pathway. Proc Natl Acad Sci USA 1999, 96:4372-4377. doi:

10.1073/pnas.96.8.4372

96. Cheng ZF, Zuo YH, Li ZW, Rudd KE, Deutscher MP. The vacB gene required for virulence in Shigella flexneri and Escherichia coli encodes the exoribonuclease RNase R. J Biol Chem 1998, 273:14077-14080. doi: 10.1074/jbc.273.23.14077 
97. Liou GG, Chang HY, Lin CS, Lin-Chao S. DEAD box RhlB RNA helicase physically associates with exoribonuclease PNPase to degrade double-stranded RNA independent of the degradosome-assembling region of RNase E. J Biol Chem 2002, 277:41157-41162. doi: 10.1074/jbc.M206618200

98. Py B, Higgins CF, Krisch HM, Carpousis AJ. A DEAD-box RNA helicase in the Escherichia coli RNA degradosome. Nature 1996, 381:169-172. doi: $10.1038 / 381169 \mathrm{a} 0$

99. Liang W, Rudd KE, Deutscher MP. A Role for REP Sequences in Regulating Translation. Mol Cell 2015, 58:431-439. doi: 10.1016/j.molcel.2015.03.019

100. Coburn GA, Mackie GA. Degradation of mRNA in Escherichia coli: An old problem with some new twists. Progress in Nucl Acid Res and Mol Biol 1999, 62:55-108.

101. Chaney SG, Boyer PD. Incorporation of water oxygens into intracellular nucleotides and RNA. II. Predominantly hydrolytic RNA turnover in Escherichia coli. J Mol Biol 1972, 64:581-591.

102. Deutscher MP. Maturation and degradation of ribosomal RNA in bacteria. Prog Mol Biol Transl Sci 2009, 85:369-391. doi: 10.1016/S0079-6603(08)00809-X

103. Mohanty BK, Kushner SR. Genomic analysis in Escherichia coli demonstrates differential roles for polynucleotide phosphorylase and RNase II in mRNA abundance and decay. Mol Microbiol 2003, 50:645-658. doi: 10.1046/j.1365-2958.2003.03724.x

104. Hajnsdorf E, Steier O, Coscoy L, Teysset L, Régnier P. Roles of RNase E, RNase II and PNPase in the degradation of the rpsO transcripts of Escherichia coli: stabilizing function of RNase II and evidence for efficient degradation in an ams pnp rnb mutant. EMBO J 1994, 13:3368-3377. 
105. Pobre V, Arraiano CM. Next generation sequencing analysis reveals that the ribonucleases RNase II, RNase R and PNPase affect bacterial motility and biofilm formation in E. coli. BMC Genomics 2015, 16:72. doi: 10.1186/s12864-015-1237-6

106. Sulthana S, Deutscher MP. Multiple exoribonucleases catalyze maturation of the $3^{\prime}$ terminus of 16S ribosomal RNA (rRNA). J Biol Chem 2013, 288:12574-12579. doi: 10.1074/jbc.C113.459172

107. Mohanty BK, Kushner SR. Ribonuclease P processes polycistronic tRNA transcripts in Escherichia coli independent of ribonuclease E. Nucl Acids Res 2007, 35:76147625. doi: $10.1093 / \mathrm{nar} / \mathrm{gkm} 917$

108. Mohanty BK, Kushner SR. Processing of the Escherichia coli leuX tRNA transcript, encoding tRNA(Leu5), requires either the 3'5' exoribonuclease polynucleotide phosphorylase or RNase P to remove the Rho-independent transcription terminator. Nucl Acids Res 2010, 38:597-607. doi: 10.1093/nar/gkp997

109. Reuven NB, Zhou ZH, Deutscher MP. Functional overlap of tRNA nucleotidyltransferase, poly(A) polymerase I, and polynucleotide phosphorylase. $J$ Biol Chem 1997, 272:33255-33259. doi: 10.1074/jbc.272.52.33255

110. Maes A, Gracia C, Hajnsdorf E, Régnier P. Search for poly(A) polymerase targets in E. coli reveals its implication in surveillance of Glu tRNA processing and degradation of stable RNAs. Mol Microbiol 2012, 83:436-451. doi: 10.1111/j.13652958.2011.07943.x

111. Li Z, Deutscher MP. Maturation pathways for E. coli tRNA precursors: a random multienzyme process in vivo. Cell 1996, 86:503-512. doi: 10.1016/S0092$8674(00) 80123-3$ 
112. Cheng ZF, Deutscher MP. Quality control of ribosomal RNA mediated by polynucleotide phosphorylase and RNase R. Proc Natl Acad Sci USA 2003, 100:6388-6393. doi: 10.1073/pnas. 1231041100

113. Li ZW, Reimers S, Pandit S, Deutscher MP. RNA quality control: degradation of defective transfer RNA. EMBO J 2002, 21:1132-1138. doi: 10.1093/emboj/21.5.1132

114. Kaplan R, Apirion D. The involvement of ribonuclease I, ribonuclease II, and polynucleotide phosphorylase in the degradation of stable ribonucleic acid during carbon starvation in Escherichia coli. J Biol Chem 1974, 249:149-151.

115. Basturea GN, Zundel MA, Deutscher MP. Degradation of ribosomal RNA during starvation: comparison to quality control during steady-state growth and a role for RNase PH. RNA 2011, 17:338-345. doi: 10.1261/rna.2448911

116. Piir K, Paier A, Liiv A, Tenson T, Maivali U. Ribosome degradation in growing bacteria. EMBO Rep 2011, 12:458-462. doi: 10.1038/embor.2011.47

117. Sim S, Wolin SL. Emerging roles for the Ro $60-\mathrm{kDa}$ autoantigen in noncoding RNA metabolism. WIREs-RNA 2011, 2:686-699. 10.1002/wrna.85

118. Wurtmann EJ, Wolin SL. A role for a bacterial ortholog of the Ro autoantigen in starvation-induced rRNA degradation. Proc Natl Acad Sci U S A 2010, 107:40224027. doi: 10.1073/pnas. 1000307107

119. Chen X, Taylor DW, Fowler CC, Galan JE, Wang HW, Wolin SL. An RNA degradation machine sculpted by Ro autoantigen and noncoding RNA. Cell 2013, 153:166-177. doi: 10.1016/j.cell.2013.02.037

120. Chen X, Sim S, Wurtmann EJ, Feke A, Wolin SL. Bacterial noncoding Y RNAs are widespread and mimic tRNAs. RNA 2014, 20:1715-1724. doi:

10.1261/rna.047241.114 
121. Saramago M, Barria C, Dos Santos RF, Silva IJ, Pobre V, Domingues S, Andrade JM, Viegas SC, Arraiano CM. The role of RNases in the regulation of small RNAs. Curr Opin Microbiol 2014, 18:105-115. doi: 10.1016/j.mib.2014.02.009

122. Andrade JM, Pobre V, Matos AM, Arraiano CM. The crucial role of PNPase in the degradation of small RNAs that are not associated with Hfq. RNA. 2012, 18:844-855. doi: 10.1261/rna.029413.111

123. De Lay N, Gottesman S. Role of polynucleotide phosphorylase in sRNA function in Escherichia coli. RNA. 2011, 17:1172-1189.

124. Andrade JM, Arraiano CM. PNPase is a key player in the regulation of small RNAs that control the expression of outer membrane proteins. $R N A .2008,14: 543-551$. doi: 10.1261/rna. 683308

125. Piazza F, Zappone M, Sana M, Briani F, Dehò G. Polynucleotide phosphorylase of Escherichia coli is required for the establishment of bacteriophage P4 immunity. $J$ Bacteriol 1996, 178:5513-5521.

126. Briani F, Del Vecchio E, Migliorini D, Hajnsdorf E, Régnier P, Ghisotti D, Dehò G. RNase E and polyadenyl polymerase I are involved in maturation of CI RNA, the P4 phage immunity factor. $J$ Mol Biol 2002, 318:321-331. doi: 10.1016/S00222836(02)00085-2

127. Weinberg Z, Wang JX, Bogue J, Yang J, Corbino K, Moy RH, Breaker RR. Comparative genomics reveals 104 candidate structured RNAs from bacteria, archaea, and their metagenomes. Genome Biol 2010, 11:R31. doi: 10.1186/gb-2010-11-3-r31

128. Sesto N, Touchon M, Andrade JM, Kondo J, Rocha EP, Arraiano CM, Archambaud C, Westhof E, Romby P, Cossart P. A PNPase dependent CRISPR System in Listeria. PLoS Genet 2014, 10:e1004065. doi: 10.1371/journal.pgen.1004065 
129. Luttinger A, Hahn J, Dubnau D. Polynucleotide phosphorylase is necessary for competence development in Bacillus subtilis. Mol Microbiol 1996, 19:343-356. doi: 10.1046/j.1365-2958.1996.380907.x

130. Haddad N, Burns CM, Bolla JM, Prevost H, Federighi M, Drider D, Cappelier JM. Long-term survival of Campylobacter jejuni at low temperatures is dependent on polynucleotide phosphorylase activity. Appl Environ Microbiol 2009, 75:7310-7318. doi: 10.1128/Aem.01366-09

131. Clements MO, Eriksson S, Thompson A, Lucchini S, Hinton JCD, Normark S, Rhen M. Polynucleotide phosphorylase is a global regulator of virulence and persistency in Salmonella enterica. Proc Natl Acad Sci USA 2002, 99:8784-8789. doi: 10.1073/pnas.132047099

132. Awano N, Inouye M, Phadtare S. RNase activity of polynucleotide phosphorylase is critical at low temperature in Escherichia coli and is complemented by RNase II. $J$ Bacteriol 2008, 190:5924-5933. doi: 10.1128/Jb.00500-08

133. Zhou Z, Deutscher MP. An essential function for the phosphate-dependent exoribonucleases RNase PH and polynucleotide phosphorylase. J Bacteriol 1997, 179:4391-4395.

134. Xia B, Ke HP, Inouye M. Acquirement of cold sensitivity by quadruple deletion of the $\operatorname{csp} A$ family and its suppression by PNPase S1 domain in Escherichia coli. Mol Microbiol 2001, 40:179-188. doi: 10.1046/j.1365-2958.2001.02372.x

135. Neuhaus K, Rapposch S, Francis KP, Scherer S. Restart of exponential growth of cold-shocked Yersinia enterocolitica occurs after down-regulation of $\operatorname{csp} A 1 / A 2$ mRNA. J Bacteriol 2000, 182:3285-3288. doi: 10.1128/JB.182.11.3285-3288.2000

136. Lopez D, Vlamakis H, Kolter R. Biofilms. Cold Spring Harb Perspect Biol 2010, 2:a000398. doi: 10.1101/cshperspect.a000398 
137. Carzaniga T, Antoniani D, Dehò G, Briani F, Landini P. The RNA processing enzyme polynucleotide phosphorylase negatively controls biofilm formation by repressing poly-N-acetylglucosamine (PNAG) production in Escherichia coli C. BMC Microbiol 2012, 12:270. doi: 10.1186/1471-2180-12-270

138. Kim SH, Wei CI. Molecular Characterization of Biofilm Formation and Attachment of Salmonella enterica Serovar Typhimurium DT104 on Food Contact Surfaces. $J$ Food Protect 2009, 72:1841-1847.

139. Rosenzweig JA, Chopra AK. The exoribonuclease Polynucleotide Phosphorylase influences the virulence and stress responses of yersiniae and many other pathogens. Front Cell Infect Microbiol 2013, 3:81. doi: 10.3389/fcimb.2013.00081

140. Bonnin RA, Bouloc P. RNA Degradation in Staphylococcus aureus: Diversity of Ribonucleases and Their Impact. Int J Genomics 2015, 2015:395753. doi: $10.1155 / 2015 / 395753$

141. Rosenzweig JA, Weltman G, Plano GV, Schesser K. Modulation of Yersinia type three secretion system by the S1 domain of polynucleotide phosphorylase. J Biol Chem 2005, 280:156-163. doi: 10.1074/jbc.M405662200

142. Matos RG, Barria C, Moreira RN, Barahona S, Domingues S, Arraiano CM. The importance of proteins of the RNase II/RNB-family in pathogenic bacteria. Front Cell Infect Microbiol 2014, 4:68. doi: 10.3389/fcimb.2014.00068

143. Charpentier X, Faucher SP, Kalachikov S, Shuman HA. Loss of RNase R induces competence development in Legionella pneumophila. J Bacteriol 2008, 190:81268136. doi: 10.1128/JB.01035-08

144. Purusharth RI, Madhuri B, Ray MK. Exoribonuclease R in Pseudomonas syringae is essential for growth at low temperature and plays a novel role in the $3^{\prime}$ end processing 
of 16 and 5 S ribosomal RNA. J Biol Chem 2007, 282:16267-16277. doi: 10.1074/jbc.M605588200

145. Erova TE, Kosykh VG, Fadl AA, Sha J, Horneman AJ, Chopra AK. Cold shock exoribonuclease $\mathrm{R}(\mathrm{VacB})$ is involved in Aeromonas hydrophila pathogenesis. $J$ Bacteriol 2008, 190:3467-3474. doi: 10.1128/JB.00075-08

146. Hayakawa H, Kuwano M, Sekiguchi M. Specific binding of 8-oxoguanine-containing RNA to polynucleotide phosphorylase protein. Biochemistry 2001, 40:9977-9982. doi: 10.1021/Bi010595q

147. Wu J, Jiang Z, Liu M, Gong X, Wu S, Burns CM, Li Z. Polynucleotide phosphorylase protects Escherichia coli against oxidative stress. Biochemistry 2009, 48:2012-2020. doi: $10.1021 /$ bi801752p

148. Wurtmann EJ, Wolin SL. RNA under attack: cellular handling of RNA damage. Crit Rev Biochem Mol Biol 2009, 44:34-49. doi: 10.1080/10409230802594043

149. Alonso JC, Cardenas PP, Sanchez H, Hejna J, Suzuki Y, Takeyasu K. Early steps of double-strand break repair in Bacillus subtilis. DNA Repair (Amst) 2013, 12:162-176. doi: 10.1016/j.dnarep.2012.12.005

150. Register JC, Griffith J. $10 \mathrm{~nm}$ RecA Protein Filaments Formed in the Presence of Mg2+ and ATP-gamma-S May Contain RNA. Mol \& General Genetics 1985, 199:415-420. doi: 10.1007/Bf00330752

151. Ishii R, Nureki O, Yokoyama S. Crystal structure of the tRNA processing enzyme RNase PH from Aquifex aeolicus. J Biol Chem 2003, 278:32397-32404.

152. Lorentzen E, Conti E. Structural basis of 3' end RNA recognition and exoribonucleolytic cleavage by an exosome RNase PH core. Mol Cell 2005, 20:473481. 
153. Liu Q, Greimann JC, Lima CD. Reconstitution, activities, and structure of the eukaryotic RNA exosome. Cell 2006, 127:1223-1237. doi: 10.1016/j.cell.2006.10.037

154. Zuker M. Mfold web server for nucleic acid folding and hybridization prediction. Nucl Acids Res 2003, 31:3406-3415.

\section{FIGURE CAPTIONS}

Fig. 1. Structural similarities between PNPase, RNase PH and the exosomes. (A) The homotrimeric structure of the $E c$ PNPase (PDB ID: $3 \mathrm{CDI}^{34}$ ) and the hexameric rings of RNase $\mathrm{PH}$, archaeal and eukaryotic exosomes (PDB ID: 1UDN, ${ }^{151} 2 \mathrm{C} 37^{152}$ and $2 \mathrm{NN} 6,{ }^{153}$ respectively) are reported. In the exosomes, only the subunits constituting the rings are shown in colour and named. (B) Domain structure of bacterial PNPase.

FIG. 2. Regulation of PNPase expression. Detailed explanation of the model and supporting references are provided in the text. The pnp primary and processed transcripts have been drawn according to the most stable secondary structure predicted by mfold. ${ }^{154}$ Different regions of $p n p$ mRNA are represented by lines of different colours: turquoise, $p n p$ coding region; black, 5'-UTR of the processed pnp mRNA; blue, stem-loop removed by the RNase III staggered cuts; green, sRNA37. The 5'-tri- and monophosphate ends of primary and processed RNAs, respectively, are indicated by the number of arrow nocks, and the 3'$\mathrm{OH}$ ends by arrowheads. Other symbols are explained in the box at the bottom of the figure. a) The pnp primary transcript is translatable and stable in the absence of RNase III. PNPase acts as a translation repressor $(\perp)$, probably by competing with $\mathrm{S} 1$ ribosomal protein for mRNA binding. However, the native transcript is quickly processed by RNase III, which 
makes two staggered cuts in the long hairpin within the 5'-UTR; b) RNase III cleavage removes about half of the stem loop; the processed pnp mRNA with the small RNA37 annealed at its 5'-end is still translatable and stable; c) PNPase degrades the small RNA37; d) the processed pnp mRNA with a single stranded 5'-end is not translation proficient and is functionally inactivated by a first RNase E cut within the pnp ORF; e) upon RNase E cleavage, rapid degradation of the pnp mRNA ensues.

\section{Related Articles}

\begin{tabular}{|l|l|}
\hline Article ID & \multicolumn{1}{|c|}{ Article title } \\
\hline & $\begin{array}{l}\text { Focus: Connections between 3' end processing and DNA } \\
\text { repair }\end{array}$ \\
\hline & Influence of the 5' end on bacterial expression/decay \\
\hline
\end{tabular}



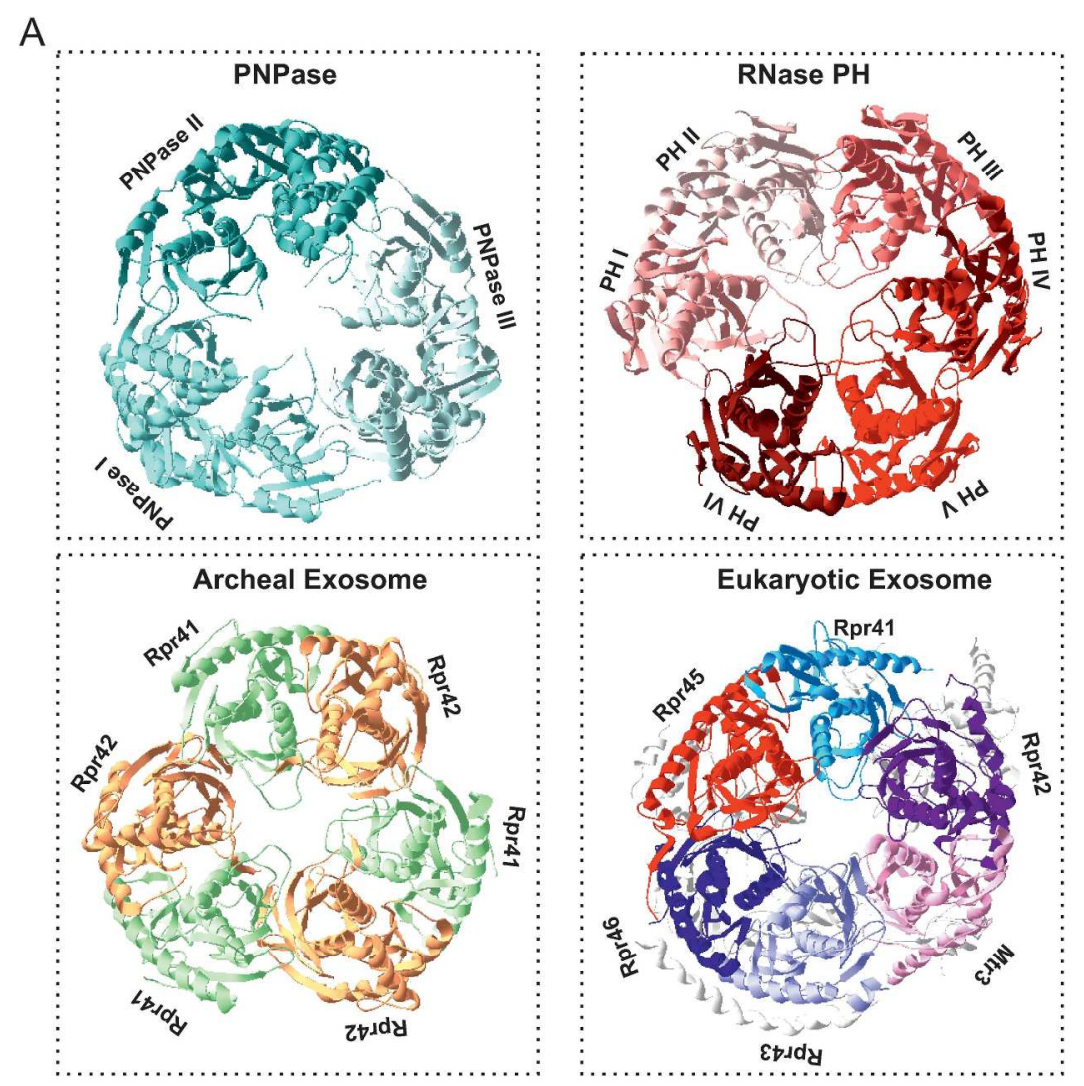

B

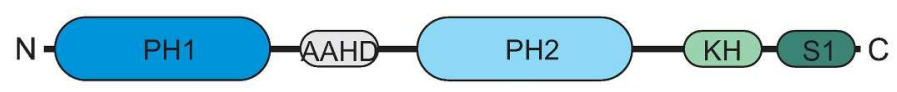

\section{Fig. 1}

Fig. 1. Structural similarities between PNPase, RNase PH and the exosomes. (A) The homotrimeric structure of the ECPNPase (PDB ID: $3 \mathrm{CDI}^{34}$ ) and the hexameric rings of RNase $\mathrm{PH}$, archaeal and eukaryotic exosomes (PDB ID: 1 UDN, ${ }^{151} 2 \mathrm{C} 7^{152}$ and $2 \mathrm{NN6},{ }^{153}$ respectively) are reported. In the exosomes, only the subunits constituting the rings are shown in colour and named. (B) Domain structure of bacterial PNPase. $196 \times 291 \mathrm{~mm}(300 \times 300$ DPI $)$ 
a

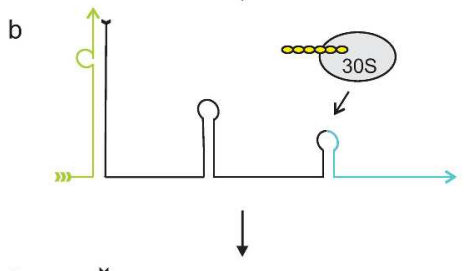

c

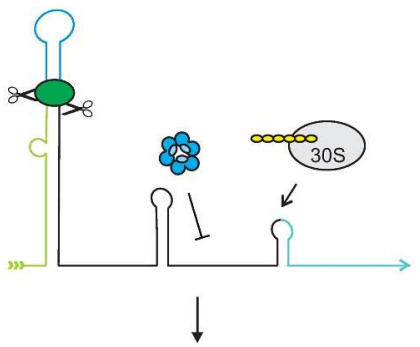

d
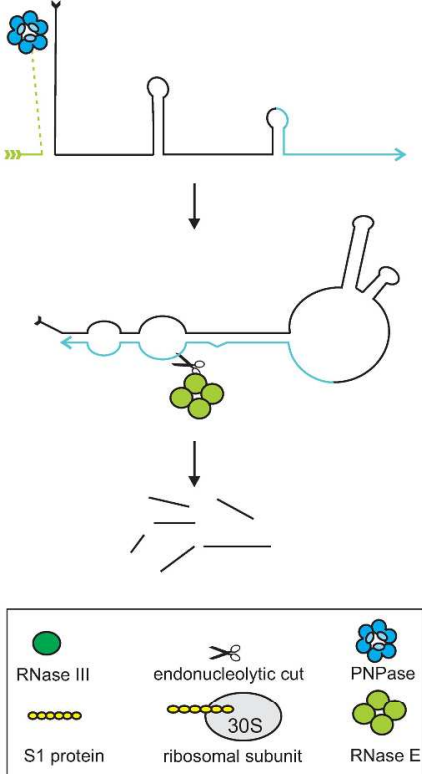

Fig. 2

FIG. 2. Regulation of PNPase expression. Detailed explanation of the model and supporting references are provided in the text. The pnp primary and processed transcripts have been drawn according to the most stable secondary structure predicted by mfold. ${ }^{154}$ Different regions of $p n p$ mRNA are represented by lines of different colours: turquoise, $p n p$ coding region; black, 5'-UTR of the processed $p n p$ mRNA; blue, stem-loop removed by the RNase III staggered cuts; green, sRNA37. The 5'-tri- and monophosphate ends of primary and processed RNAs, respectively, are indicated by the number of arrow nocks, and the 3'-OH ends by arrowheads. Other symbols are explained in the box at the bottom of the figure. a) The pnp primary transcript is translatable and stable in the absence of RNase III. PNPase acts as a translation repressor $\left({ }^{\perp}\right)$, probably by competing with S1 ribosomal protein for mRNA binding. However, the native transcript is quickly processed by RNase III, which makes two staggered cuts in the long hairpin within the $5^{\prime}$-UTR; b) RNase III cleavage removes about half of the stem loop; the processed pnp mRNA with the small RNA37 annealed at its $5^{\prime}$-end is still translatable and stable; c) PNPase degrades the small RNA37; d) the processed $p n p$ mRNA with a single stranded $5^{\prime}$-end is not translation proficient and is functionally inactivated by a first 


1
2
3
4
5
6
7
8
9
10
11
12
13
14
15
16
17
18
19
20
21
22
23
24
25
26
27
28
29
30
31
32
33
34
35
36
37
38
39
40
41
42
43
44
45
46
47
48
49
50
51
52
53
54
55
56
57
58
60

RNase E cut within the pnp ORF; e) upon RNase E cleavage, rapid degradation of the pnp mRNA ensues. $248 \times 590 \mathrm{~mm}(300 \times 300 \mathrm{DPI})$ 